\title{
CONTACTLESS THERMODILATOMETRY OF GLASS CULLET
}

\author{
JAROSLAVA MICHÁLKOVÁ*, MÁRIA CHROMČÍKOVÁ*,**, BRANISLAV HRUŠKA*, \\ JACOB PETERSON*, ${ }^{*}$ MAREK LIŠKA**** \\ *FunGlass, A. Dubček University of Trenčin, Študentská 2, SK-911 50 Trenčin, Slovakia \\ **VILA - Joined Glass Centre of the IIC SAS, TnUAD, FChPT STU, \\ Študentská 2, SK-911 50 Trenčín, Slovakia \\ \#E-mail: marek.liska@tnuni.sk
}

Submitted April 9, 2021; accepted May 17, 2021

\begin{abstract}
Keywords: Contactless dilatometry, Glass cullet recycling, Priven 2000 method, Thermal expansion, Glass transition
Contactless dilatometry was used for the thermal analysis of a set of glass cullet samples collected in the surroundings (including the forest, gardens, etc.) of the Janštejn glass factory. The collected set of samples covered the time period of approximately one century. The glass composition was measured by X-ray fluorescence spectroscopy. A method of verifying the correctness of the contactless dilatometry results based on the Priven 2000 evaluation of thermal properties was proposed and verified.
\end{abstract}

\section{INTRODUCTION}

Thermodilatometry can be used to test a wide range of materials including traditional and advanced ceramics, glasses, metals and polymers. The basic types of dilatometers are horizontal and vertical. Optical (contactless) thermodilatometry is an original and flexible technique capable of measuring changes in length without contacting a sample [1-3]. The contactless measuring principle greatly simplifies the sample preparation process. The shape of the sample is not as critical as with contact dilatometry because the software automatically measures the linear dimension of the sample. Optical dilatometry is a very useful nondestructive method for measuring samples of irregular shapes which allows this method to be used to measure the dilatation properties of historical glass or glass cullet.

In today's ecological age, there is a growing interest in recycling various waste and, thus, there is increasing interest and pressure to recycle more waste materials that have been collected and then transported to the untouched nature. For many years, shards from glassworks were also considered to be waste and an unnecessary material. Nowadays, glassworks no longer "dispose" of their glass waste in this way, but process it ecologically by recycling it again. One of the environmental ways of processing such a material is the production of sintered boards. Their use is various, for example, in construction or the furniture industry. However, these fields of application are rigorously restricted by particular technical norms prescribing the minimal values of some mechanical properties like fracture toughness, etc. Therefore, the production technology must be optimised to fulfil these demands. From this point of view, it is very important to optimise the time temperature schedule and the maximum size of the sintered cullet particles. Both of these features are determined by the thermal expansion and by the upper and lower annealing temperature, which are related to the glass viscosity temperature dependence [3-7] (the upper annealing temperature corresponds to a viscosity of $10^{13} \mathrm{dPa} \cdot \mathrm{s}$, and the lower annealing temperature corresponds to a viscosity of $\left.10^{14.5} \mathrm{dPa} \cdot \mathrm{s}\right)$. As the measurement of viscosity of small pieces of cullet with an irregular shape is practically impossible, the glass transition temperature (approximately corresponding to a viscosity of $10^{13} \mathrm{dPa} \cdot \mathrm{s}$ ) can be used for a rough estimate of the annealing temperature range.

In some cases, the results obtained by a contactless thermo-dilatometry are incorrect due to the sample's characteristics, i.e., due to the partial crystallisation or due to the irregular shape of the sample bottom causing the movement of the sample during heating to higher temperatures or due to some invisible cracks/ defects inside the sample. Solving such problems - with the exception of crystallisation - in the case of glass cullet resides in the repeated measurement of more samples with the same composition. However, this is not possible in the case of unique samples of historical glass/artifacts. If the glass composition is known (e.g., measured by non-destructive X-ray fluorescence microspectroscopy), then the result of the thermodilatometric measurement may be confirmed by calculation of the measured properties by some appropriate approximate method. The aim of the present paper is the application of the Priven 2000 method for verification of the glass transition temperature and thermal expansion coefficient values measured by contactless thermodilatometry on a set of samples of glass cullet from the Janštejn glass factory. 


\section{EXPERIMENTAL}

The description of the studied cullet samples is summarised in Table 1. The chemical composition of the collected glass cullet measured by X-ray fluorescence spectroscopy (XRF) was published in our previous work [8]. The minimum and maximum content of the individual oxides found in the studied set of glass cullet samples are summarised in Table II. Negligible amounts of $\mathrm{TiO}_{2}, \mathrm{As}_{2} \mathrm{O}_{3}, \mathrm{CoO}, \mathrm{MnO}, \mathrm{CdO}$, and $\mathrm{NiO}$ are not included. Some samples were not analysed due to small amount of cullet.

An optical (contactless) thermo-dilatometer DIL806 (TA Instruments) [1] was used for the measurement of the coefficient of thermal expansion, $\alpha_{g}$, and the glass transition temperature, $T_{\mathrm{g}}$. The cullet samples with approximate dimensions ranging from $5 \mathrm{~mm}$ to $17 \mathrm{~mm}$ were measured. Thermodilatometric curves were recorded during heating from room temperature up to $900^{\circ} \mathrm{C}$ by a heating rate of $5^{\circ} \mathrm{C} \cdot \mathrm{min}^{-1}$. Some samples were not measured due to a small amount or non-homogeneous character. Thus, from total amount of 110 cullet samples, only 95 samples were analysed by XRF and thermodilatometry.

The coefficient of thermal expansion, $\alpha_{g}$, and the glass transition temperature, $T_{\mathrm{g}}$, were also evaluated by the Priven 2000 method $[9,10]$ using the glass chemical composition measured by X-ray fluorescence spectroscopy. All the details of A.I. Priven's structural model [9] were originally published in his Doctoral Thesis (St. Petersburg, 2002 - in Russian). Model calculations can be performed using the SciGlass database [10]. The model is valid for almost all known types of oxide glasses: silicate, germanate, borate, aluminate, phosphate, vanadate, molybdate, niobate, arsenite, tellurite, tungstate, etc., including mixed systems. In total, sixtyfour oxides are involved in the calculations: $\mathrm{Li}_{2} \mathrm{O}, \mathrm{Na}_{2} \mathrm{O}$, $\mathrm{K} 2 \mathrm{O}, \mathrm{Rb}_{2} \mathrm{O}, \mathrm{Cs}_{2} \mathrm{O}, \mathrm{Cu}_{2} \mathrm{O}, \mathrm{Ag}_{2} \mathrm{O}, \mathrm{Tl}_{2} \mathrm{O}, \mathrm{BeO}, \mathrm{MgO}, \mathrm{CaO}$, $\mathrm{SrO}, \mathrm{BaO}, \mathrm{MnO}, \mathrm{CoO}, \mathrm{NiO}, \mathrm{SnO}, \mathrm{ZnO}, \mathrm{CdO}, \mathrm{PbO}, \mathrm{FeO}$, $\mathrm{CuO}, \mathrm{B}_{2} \mathrm{O}_{3}, \mathrm{Al}_{2} \mathrm{O}_{3}, \mathrm{Ga}_{2} \mathrm{O}_{3}, \mathrm{Fe}_{2} \mathrm{O}_{3}, \mathrm{Cr}_{2} \mathrm{O}_{3}, \mathrm{Ti}_{2} \mathrm{O}_{3}, \mathrm{In}_{2} \mathrm{O}_{3}$, $\mathrm{La}_{2} \mathrm{O}_{3}, \mathrm{Y}_{2} \mathrm{O}_{3}, \mathrm{Sc}_{2} \mathrm{O}_{3}, \mathrm{Gd}_{2} \mathrm{O}_{3}, \mathrm{Sm}_{2} \mathrm{O}_{3}, \mathrm{Nd}_{2} \mathrm{O}_{3}, \mathrm{Pr}_{2} \mathrm{O}_{3}$, $\mathrm{Tb}_{2} \mathrm{O}_{3}, \mathrm{Dy}_{2} \mathrm{O}_{3}, \mathrm{Er}_{2} \mathrm{O}_{3}, \mathrm{Yb}_{2} \mathrm{O}_{3}, \mathrm{As}_{2} \mathrm{O}_{3}, \mathrm{Sb}_{2} \mathrm{O}_{3}, \mathrm{Bi}_{2} \mathrm{O}_{3}$,
$\mathrm{SiO}_{2}, \mathrm{GeO}_{2}, \mathrm{ThO}_{2}, \mathrm{VO}_{2}, \mathrm{HfO}_{2}, \mathrm{SeO}_{2}, \mathrm{TeO}_{2}, \mathrm{PbO}_{2}, \mathrm{TiO}_{2}$, $\mathrm{SnO}_{2}, \mathrm{ZrO}_{2}, \mathrm{CeO}_{2}, \mathrm{MnO}_{2}, \mathrm{P}_{2} \mathrm{O}_{5}, \mathrm{~V}_{2} \mathrm{O}_{5}, \mathrm{Nb}_{2} \mathrm{O}_{5}, \mathrm{Ta}_{2} \mathrm{O}_{5}$, $\mathrm{MoO}_{3}, \mathrm{WO}_{3}$, and $\mathrm{SO}_{3}$. As can be seen in Table II, all the oxides with a non-negligible abundance are included in the Priven 2000 method.

Table 2. Oxide content in the studied samples of the glass cullet in wt. \% [8], only the oxides with a maximum content higher than 1 wt. $\%$ are listed.

\begin{tabular}{lrrrr}
\hline Oxide & Average & Minimum & Maximum & Max-Min \\
\hline $\mathrm{SiO}_{2}$ & 73.334 & 65.100 & 78.510 & 13.410 \\
$\mathrm{Al}_{2} \mathrm{O}_{3}$ & 2.175 & 0.050 & 7.590 & 7.540 \\
$\mathrm{Na}_{2} \mathrm{O}$ & 12.674 & 2.670 & 18.781 & 16.111 \\
$\mathrm{~K}_{2} \mathrm{O}$ & 3.896 & 0.147 & 14.140 & 13.993 \\
$\mathrm{MgO}$ & 0.138 & 0.000 & 3.515 & 3.515 \\
$\mathrm{CaO}$ & 5.236 & 0.170 & 8.890 & 8.720 \\
$\mathrm{Fe}_{2} \mathrm{O}_{3}$ & 0.136 & 0.012 & 1.353 & 1.341 \\
$\mathrm{ZnO}$ & 0.911 & 0.000 & 9.530 & 9.530 \\
$\mathrm{P}_{2} \mathrm{O}_{5}$ & 0.045 & 0.000 & 1.750 & 1.750 \\
$\mathrm{PbO}$ & 0.236 & 0.000 & 4.370 & 4.370 \\
$\mathrm{Cr}_{2} \mathrm{O}_{3}$ & 0.025 & 0.000 & 1.140 & 1.140 \\
$\mathrm{CuO}$ & 0.042 & 0.000 & 1.715 & 1.715 \\
$\mathrm{BaO}$ & 0.157 & 0.000 & 2.326 & 2.326 \\
$\mathrm{Sb}_{2} \mathrm{O}_{3}$ & 0.063 & 0.000 & 1.010 & 1.010 \\
\hline
\end{tabular}

\section{RESULTS AND DISCUSSION}

In the first step, the measured values of the thermal expansion coefficient and the glass transition temperature were compared with the values calculated by the Priven 2000 method. According the published data [10], the expected standard deviation of the residuals of the estimated values of $\alpha_{g}$ and $T_{\mathrm{g}}$ are $9.6 \cdot 10^{-7}{ }^{\circ} \mathrm{C}^{-1}$ and $43^{\circ} \mathrm{C}$, respectively.

Comparing the experimental $\alpha_{g}$ values with the estimated ones indicates the main differences in some of the cases where unacceptably high (e.g., over $250 \cdot 10^{-7}{ }^{\circ} \mathrm{C}^{-1}$ ) experimental values were measured. Similarly, for the $T_{\mathrm{g}}$ values, some extremely high values were measured for some samples. The probable source of these differences

Table 1. Summary of the studied samples of glass cullet.

\begin{tabular}{clccc}
\hline Series & Locality & Age / years & Sample No. & Abbreviation \\
\hline 1 & ZA (garden) & 50 & $1-11$ & ZA1 - ZA11 \\
2 & ZS (garden) & 50 & $12-18$ & ZS12 - ZS18 \\
3 & LES (forest) & 50 & $19-25$ & LES19 - LES25 \\
4 & CH (mill) & 50 & $26-40$ & CH26 - CH40 \\
5 & SJ (glasswork) & $20-50$ & $41-49$ & SJS41 - SJS49 \\
6 & SJM (glasswork) & $50-150$ & $50-63$ & SJM50 - SJM63 \\
7 & SJR (glasswork) & 50 & $64-72$ & SJR64 - SJR72 \\
8 & NK (forest) & 60 & $73-79$ & NK73 - NK79 \\
9 & VK (forest) & 80 & $80-89$ & VK80 - VK89 \\
10 & TL (forest) & 100 & $90-95$ & TL90 - TL95 \\
11 & END (underground) & $96-110$ & END96- END110 \\
\hline
\end{tabular}


can be identified as the sample's movement during the measurement caused by the irregular sample shape with the bottom part touching the measurement chamber base at only few sharp points. In some cases, internal cracks and the partially crystalised character of the measured samples are the reason for the large difference between the calculated and measured values.

The standard deviation of the residuals for $T_{\mathrm{g}}$ values was $56.1{ }^{\circ} \mathrm{C}$, and the mean difference between the calculated and measured values was $5.2{ }^{\circ} \mathrm{C}$. After removing sixteen outliers defined as points with an absolute deviation higher than $75^{\circ} \mathrm{C}$, the standard deviation decreased to $31.4{ }^{\circ} \mathrm{C}$. This value is less than the value of $43{ }^{\circ} \mathrm{C}$ published in [10]. The mean difference increased to $16.7{ }^{\circ} \mathrm{C}$, which reflects the asymmetric distribution of the deleted outliers. Moreover, some deviations can be expected due to the fact that the experimental $T_{\mathrm{g}}$ values were evaluated from the heating thermodilatometric curve. Different cullet pieces were produced by different cooling rates and, therefore, have a different $T_{\mathrm{g}}$ - the higher cooling rate led to the higher $T_{\mathrm{g}}$ value obtained from the heating thermodilatometric curve recorded with a constant heating rate. The distribution of the differences between the calculated and measured $T_{\mathrm{g}}$ is plotted in Figure 1. It can be seen that the distribution is close to a normal probability distribution.

The standard deviation of the residuals for the $\alpha_{\mathrm{g}}$ values was $99.8 \cdot 10^{-7}{ }^{\circ} \mathrm{C}^{-1}$, and the mean difference between the calculated and measured values was $-41.6 \cdot 10^{-7}{ }^{\circ} \mathrm{C}^{-1}$. After removing fourteen outliers defined as points with an absolute deviation higher than $10^{-5}{ }^{\circ} \mathrm{C}^{-1}$, the standard deviation decreased to $43.3 \cdot 10^{-7}$ ${ }^{\circ} \mathrm{C}^{-1}$. This value is significantly higher than the value 9.6 $10^{7}{ }^{\circ} \mathrm{C}^{-1}$ published in [10]. The mean difference decreased to $-12.2 \cdot 10^{-7}{ }^{\circ} \mathrm{C}^{-1}$. The distribution of the differences between the calculated and measured $\alpha_{\mathrm{g}}$ is plotted in Figure 2. Despite the fact that the distribution of the differences is relatively well described by a normal probability distribution, the variance is unacceptably

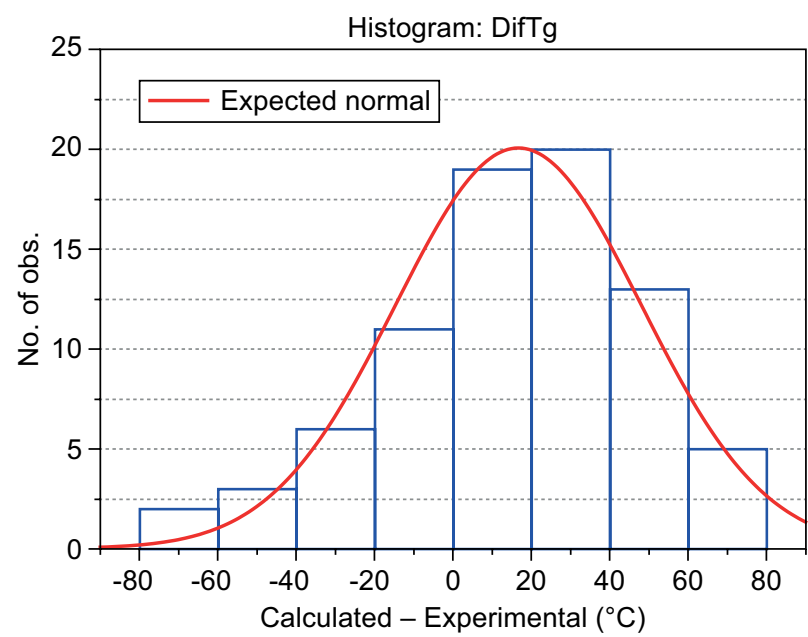

Figure 1. Distribution of the deviations between the calculated and experimental $T_{\mathrm{g}}$ values. high and indicates relatively large and frequent experimental errors.

In the next step, the average measured and calculated values of $T_{\mathrm{g}}$ and $\alpha_{\mathrm{g}}$ were evaluated for each locality reported in Table I.

The average $T_{\mathrm{g}}$ values are, together with the standard deviation (expressed by error bars), plotted in Figure 3. With the exception of the NK locality, the calculated and experimental data are roughly (i.e., within the interval of standard deviation) identical. In most cases, the calculated mean values are a little bit higher than the experimental ones. From the plotted data, the supremum of the upper annealing temperature can be roughly estimated as close to the $550{ }^{\circ} \mathrm{C}$. Moreover, it can be seen that the average $T_{\mathrm{g}}$ value is lower for the contemporary and recent glass cullet. This is in accord with the finding in [8] that contemporary and recently produced glass contain a lower amount of networkforming $\mathrm{SiO}_{2}$ and a higher amount of network-modifying $\mathrm{Na}_{2} \mathrm{O}$.

The average $\alpha_{\mathrm{g}}$ values are, together with the standard deviation (expressed by error bars), plotted in Figure 4 . It can be seen that relatively high experimental errors led to very high values of the standard deviations. On the other hand, it can be seen that within the interval of the standard deviation of the measured $a_{\mathrm{g}}$ values, the experimental and calculated values coincide. Thus, more reliable information can be obtained from the calculated $\alpha_{\mathrm{g}}$ values. The calculated thermal expansion coefficient in the range from $85 \cdot 10^{-7}{ }^{\circ} \mathrm{C}^{-1}$ to $120 \cdot 10^{-7}{ }^{\circ} \mathrm{C}^{-1}$ covers the glass cullet from all the localities. The lower content of the network-forming $\mathrm{SiO}_{2}$ and higher content of the network-modifying $\mathrm{Na}_{2} \mathrm{O}$ in the contemporary and recent glass cullet led to the higher $\alpha_{\mathrm{g}}$ values.

For fusing the contemporary and recent glass cullet, an upper annealing temperature of $490{ }^{\circ} \mathrm{C}$ can be used and the dimension of the fused particles can be adjusted to the thermal expansion coefficient ranging from $100 \cdot 10^{-7}{ }^{\circ} \mathrm{C}^{-1}$ to $120 \cdot 10^{-7}{ }^{\circ} \mathrm{C}^{-1}$.

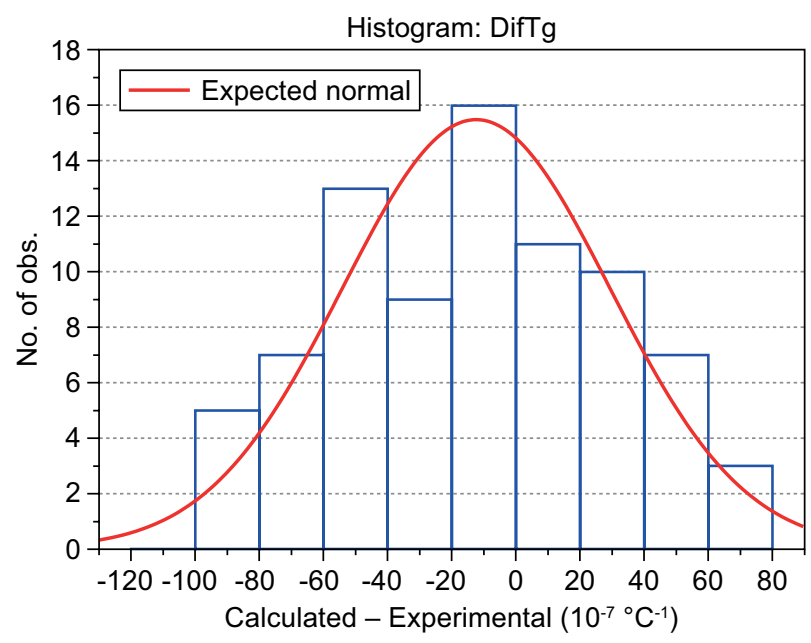

Figure 2. Distribution of the deviations between the calculated and experimental $\alpha_{\mathrm{g}}$ values. 


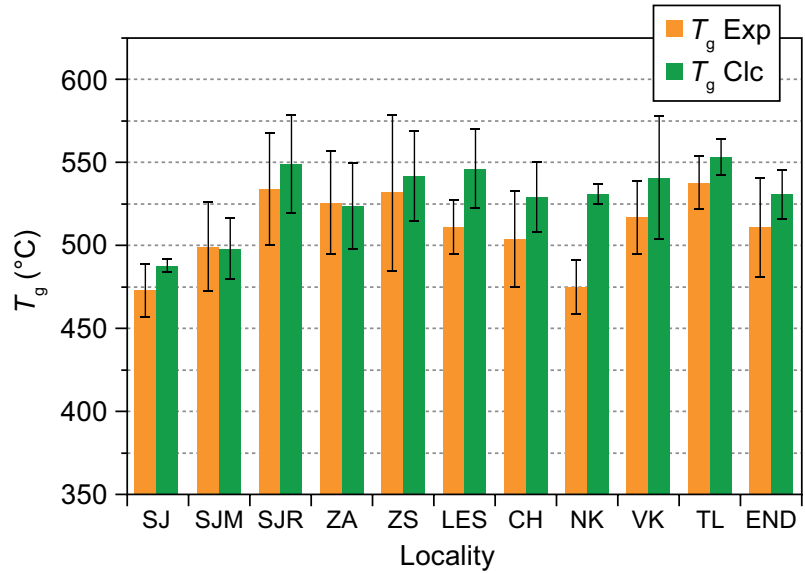

Figure 3. Average $T_{\mathrm{g}}$ for all the localities (ordered from the most contemporary to the oldest). Standard deviations are expressed by error bars.

\section{CONCLUSIONS}

The method of verifying the correctness of the contactless dilatometry results based on the Priven 2000 evaluation of thermal properties was proposed and verified. It was found that the frequent and relatively large experimental errors were observed for the glass thermal expansion coefficient measured by contactless dilatometry. On the other hand, an acceptable coincidence between the calculated and measured glass transition temperature was confirmed. The upper annealing temperature for sintering the cullet from different localities was roughly approximated to $550{ }^{\circ} \mathrm{C}$. The dimensions of the fused cullet particles from all the localities have to be adjusted to the thermal expansion coefficient ranging from $85 \cdot 10^{-7}{ }^{\circ} \mathrm{C}^{-1}$ to $120 \cdot 10^{7}{ }^{\circ} \mathrm{C}^{-1}$.

\section{Acknowledgement}

This work was supported by the Slovak Grant Agency for Science under the grant VEGA 1/0064/18, and by the projects of Interreg $V$-A - Slovakia-Czech Republic with ITMS codes $304011 C 847$ and $304011 P 822$.

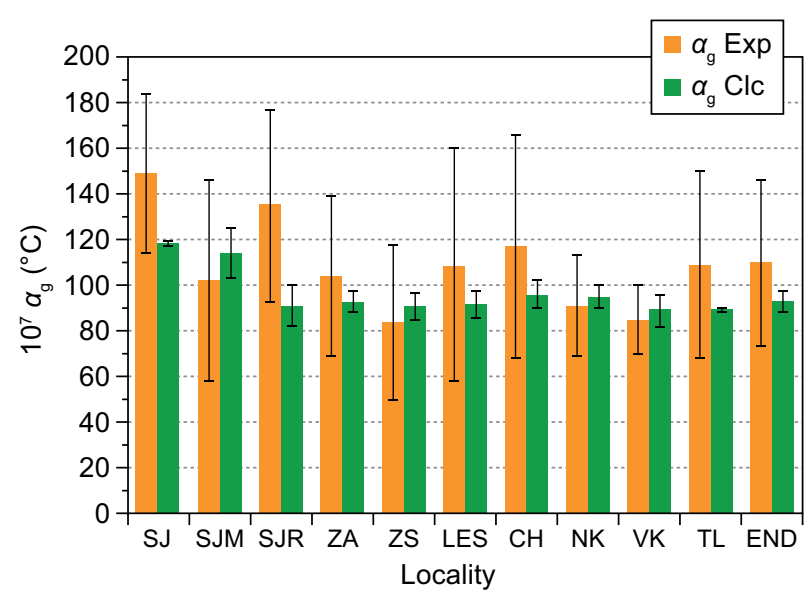

Figure 4. Average $\alpha_{\mathrm{g}}$ for all the localities (ordered from the most contemporary to the oldest). Standard deviations are expressed by error bars.

\section{REFERENCES}

1. TA Instruments (2021). www.tainstruments.com/products/ dilatometers/optical-dilatometers/.

2. Brown M.E. (1988). Thermodilatometry. In: Introduction to Thermal Analysis. Springer, Dordrecht. doi: 10.1007/97894-009-1219-9 6.

3. Hunkel M., Surm H., Steinbacher M. (2018). Dilatometry. Chap. 3. in: Vyazovkin S., Koga N., Schick C. (Eds): Handbook of Thermal Analysis and Calorimetry. $2^{\text {nd }}$ ed., Elsevier. ISBN 9780444640628.

4. Vogel W. (1994). Glass Chemistry. $2^{\text {nd }}$ Edition, Springer, Berlin. ISBN 3-540-57572-3.

5. Varshneya A.K. (2006). Fundamentals of Inorganic Glasses. $2^{\text {nd }}$ Edition, Society of Glass Technology. Sheffield.

6. Scholze H. (1991). Glass. Nature, Structure, and Properties. Springer, Berlin.

7. Hlaváč J. (1983). The Technology of Glass and Ceramics. Elsevier, Amsterdam. ISBN: 0-444-99688-5

8. Liška M., Chromčíková M., Michálková J., Dvořák M. (2020): Chemical composition of glass cullet from Janštejn. Skláŕ a keramik, 7-8, 139-142.

9. Priven A. I. (2004): General Method for Calculating the Properties of Oxide Glasses and Glass-Forming Melts from their Composition and Temperature. Glass Technology, 45, 244-254

10. Priven A.I. (2021). https://glassproperties.com/priven/. 